\title{
IMPEDANCE CARDIOGRAPHY - OLD METHOD, NEW OPPORTUNITIES. PART II. TESTING OF CARDIOVASCULAR RESPONSE TO VARIOUS FACTORS OF WORK ENVIRONMENT
}

\author{
JADWIGA SIEDLECKA ${ }^{1}$, PATRYK SIEDLECKI ${ }^{2}$, and ALICJA BORTKIEWICZ ${ }^{1}$ \\ ${ }^{1}$ Nofer Institute of Occupational Medicine, Łódź, Poland \\ Department of Work Physiology and Ergonomics \\ ${ }^{2}$ Medical University of Lodz, Łódź, Poland \\ Faculty of Medicine
}

\begin{abstract}
Impedance cardiography seems to be a very good, although underappreciated diagnostic method. What may distinguish it from among the many research methods is the fact that it enables non-invasive monitoring of cardiac output, stroke volume and systemic vascular resistance. Holter recording of the hemodynamic parameters makes it possible to study them not only in stationary (hospital, outpatient clinic) conditions, but also during household or professional activities, e.g., during road vehicle driving. Assessment of the trends of changes in the circulatory system of the employee at work makes it possible to judge whether the type of work performed by the worker is well tolerated - whether it is not too hard or too stressful. This is important, therefore, impedance cardiography can be extensively used in occupational medicine. Provision of preventive care to workers according to current standards requires, on the one hand, the use of the latest diagnostic methods while, on the other hand, the methods must be inexpensive, because otherwise the employer would not be able or willing to pay the associated costs. Impedance cardiography meets those criteria; however, few data is available in literature worldwide on the use of this method in the research on the impact of occupational work on cardiovascular responses of the employees. This work reports the use of impedance cardiography in studies on the various aspects of work environment.
\end{abstract}

Key words:

Impedance cardiography, Cardiovascular system, Work environment, Occupational stress, Physical activity, Drivers' health

\section{INTRODUCTION}

The data on impedance cardiography, its diagnostic value and possible different applications suggest that it may also be very useful in occupational medicine. Holter recording of the hemodynamic parameters makes it possible to study them not only in stationary (hospital, outpatient clinic) conditions, but also during household or professional activities, e.g., during road vehicle driving. Assessment of the trends of changes in the circulatory system of the employee at work makes it possible to judge whether the type of

This work was prepared in the frame of Project entitled: „Integrated system for monitoring the psychical and physical condition of road vehicle drivers to minimize hazards in road traffic" financed by Innovative Economy Programme: Priority 1. Research and Development of Modern Technologies Activity (UDA-POIG.01.03.01-10-085/09). Coordinator / project manager: Prof. Alicja Bortkiewicz, PhD.

Received: September 4, 2014. Accepted: November 20, 2014.

Corresponding author: J. Siedlecka, Nofer Institute of Occupational Medicine, Department of Work Physiology and Ergonomics, św. Teresy 8, 91-348 Łódź, Poland (e-mail: jadzias@imp.lodz.pl). 
work performed by the worker is well tolerated - whether it is not too hard or too stressful. This is important, therefore, impedance cardiography can be extensively used in occupational medicine.

Provision of preventive care to workers according to current standards requires, on the one hand, the use of the latest diagnostic methods while, on the other hand, the methods must be inexpensive, because otherwise the employer would not be able or willing to pay the associated costs. Impedance cardiography meets those criteria; however, few data is available in literature worldwide on the use of this method in the research on the impact of occupational work on cardiovascular responses of the employees. This work reports the use of impedance cardiography in studies on the various aspects of work environment.

\section{OCCUPATIONAL STRESS}

One of such studies assessed the effect of occupational stress on changes in the value of pre-ejection period (PEP) during $24 \mathrm{~h} \mathrm{[1]}$. The PEP is the time between the onset of ventricular depolarization and the opening of the semilunar valves. Changes in the value of PEP reliably reflect the adrenergic regulation of the operation of the left ventricle. The study involved 67 male white-collar workers, aged 47.1 \pm 5.2 years, who underwent 24 -h ambulatory impedance cardiography (ICG) during 2 working days and 1 day off.

Occupational stress was defined according to Siegrist model as a disproportion between the effort put into the work and the reward, both in terms of financial remuneration and/or appreciation, or as excessive involvement in the work. In a group characterized by excessive involvement in work, lower absolute values of pre-ejection period were found at any time of the day during all 3 days of the experiment. Reduced PEP variability and smaller day/night PEP difference were also noted.

According to the authors of the work, such shape of the daily profile of PEP in this group of patients is an indicator of persisting $\beta$-adrenergic stimulation of the heart. This phenomenon was particularly evident during sleep. During night time, PEP elongation did not occur to such an extent as in the other groups. Moreover, this was accompanied by a decrease in the subjective assessment of sleep quality in those patients [1].

The shortening of the pre-ejection period resulting from increased sympathetic tension was also confirmed by Mezzacappa et al. [2] who evaluated the effects of epinephrine injections on the function of the cardiovascular system in a group of 26 men. The epinephrine hydrochloride used in the study significantly reduced the PEP and increased stroke volume of the heart in the patients. The results show that the hemodynamic monitoring using ICG facilitates non-invasive and objective evaluation of the body's responses to stress [2]. Harris et al. obtained similar results, and additionally demonstrated that blocking the $\beta$-adrenergic receptors resulted in elongation of PEP [3]. Effects of physical exercise on the value of PEP has been also reported. Smith et al. noted that PEP tended to become shorter with increasing intensity of the exercise [4]. According to the data quoted above, it appears that PEP is a useful parameter in assessing the impact of occupational work in its wide sense on the cardiovascular system, and impedance cardiography seems to be a convenient tool for its determination.

A study on cardiovascular reactivity to stress was also carried out in a police group in Singapore. The participants included 114 men, who were asked to perform the following tasks: do mental arithmetic; read a text; recall a situation that aroused the greatest anger during the past 6 months and talk about the situation. The largest increases in mean systolic and diastolic blood pressures were observed during the execution of arithmetic and during the conversation about the situation that caused the greatest anger. Average heart rate was highest during the reading of the text and talk about the situation causing anger. The largest increase in cardiac output was observed 
when performing arithmetic tasks and when talking about the situation causing anger. Talking about the situation causing anger caused the highest increase in mean arterial pressure, cardiac output, and vascular reactivity. Differences were also observed in hemodynamic parameters between the different ethnic groups (Malays, Indians and Chinese) of the policemen [5].

Problems of monitoring cardiovascular response to stress were also studied by Salomon et al. [6]. They determined the hemodynamic profile of the persons who had been subjected to a psychological stressor by asking them to prepare and deliver a speech. The study involved 50 people with major depressive disorders, 25 people with remitted major depression, and 45 healthy individuals as the control group. The effects of stress on the cardiovascular system were reflected by significant changes in hemodynamic parameters during both speech preparation and delivering. Changes in systolic blood pressure, heart rate and PEP were recorded during speech preparation, while speech delivering was associated with changes in heart rate, PEP, and cardiac output. Changes in the values of systolic blood pressure in the group with depression were different than in the healthy and the remitted major depression groups. The authors conclude that people with depression show lower cardiovascular reactivity to a stressor such as delivering a speech than the healthy and the remitted major depression groups [6].

Similar studies were conducted by Bosch et al. [7] in a group of 61 healthy students aged 18-24 years, who also were asked to prepare and deliver a speech. Evaluation of the impact of such a strong stressor on hemodynamic parameters showed primarily changes in the PEP of the respondents [7]. The studies show that changes in the value of the pre-ejection period may be a good indicator of cardiovascular response to various stressors.

Elevated hemodynamic response to stress and elevated blood pressure at rest has been observed in people likely to develop hypertension. Marrero et al. [8] analyzed the mechanism of hypertension to see which mechanism of hypertension development - increased vascular resistance, or increased cardiac output - is likely to be responsible for increase blood pressure in males affected by a specific mental stressor.

The study subjects included 33 healthy men aged 2135 years who, based on history data and results of resting blood pressure determinations, were classified into 2 groups: with a high risk (19 persons) and with a low risk (14 persons) of developing hypertension. The participants were asked to accomplish a difficult arithmetic task and respond, as quickly as possible, to the signal displayed on the monitor. Blood pressure, heart rate, cardiac output, stroke volume and systemic vascular resistance were measured at rest, during performing the arithmetic operations and during the response to the signal displayed on the monitor. Men at high risk of developing hypertension had significantly higher blood pressure, accompanied by higher vascular resistance at rest and during mental stress. Minor differences between the groups were observed in heart rate, cardiac output and stroke volume. The results confirmed that the increased systemic vascular resistance is a dominant factor in the pathogenesis of arterial hypertension [8].

\section{PHYSICAL FACTORS AND MICROCLIMATE}

The mechanisms underlying the increase in blood pressure in individuals exposed to noise were examined by Paunović et al [9]. They evaluated the changes in blood pressure, heart rate and other hemodynamic parameters in response to traffic noise. The study involved subjects (42 men, 88 women) aged $24.88 \pm 2.67$ years. The test procedure consisted of 3 stages: 10 min exposure to $89 \mathrm{dBA}$ noise, and 2 periods of relaxation in quiet ( $40 \mathrm{dBA}$ noise level) conditions before and after exposure to noise. Listening to recorded traffic noise resulted in a significant decrease in stroke volume and cardiac output and increased systemic vascular resistance. Heart rate variability and the 
general state of the autonomic nervous system remained similar in all periods of the experiment.

During exposure to noise, systolic blood pressure was seen to increase by $2 \mathrm{~mm} \mathrm{Hg}$ (95\% CI: 0.97-2.73) in women, and by $4 \mathrm{~mm} \mathrm{Hg}$ (95\% CI: 2.16-5.00) in men. Similarly, diastolic blood pressure increased by $2 \mathrm{~mm} \mathrm{Hg}$ in women (95\% CI: $0.95-2.47)$ and by about $4 \mathrm{~mm} \mathrm{Hg}$ in men (95\% CI: 2.46-5.28). Upon cessation of the noise, both systolic and diastolic blood pressure returned to the preexposure level. Experimental $10 \mathrm{~min}$ exposure to recorded 89 dBA traffic noise caused significant hemodynamic changes in young adults, including an increase in systemic vascular resistance resulting in an increase in systolic and diastolic blood pressure.

The use of impedance cardiography made it possible to explain the pathogenesis of blood pressure increase after exposure to noise. This is very important in the prevention and treatment of hypertension in people exposed to noise when working and confirms extra-auditory effects of exposure to noise [9].

Studies on the effect of noise on the increase in blood pressure using impedance cardiography were already carried out in the 1980s. Andren et al. (1980) [10] evaluated changes in blood pressure and other hemodynamic parameters (stroke volume, cardiac output and systemic vascular resistance) in 18 healthy men before and during exposure to recorded industrial noise. All measurements took place in a noise laboratory under strictly standardized conditions. Compared with resting conditions (noise level: $40 \mathrm{dBA}$ ), exposure to $95 \mathrm{dBA}$ industrial noise caused a significant increase in diastolic blood pressure, mean arterial pressure and systemic vascular resistance. There was also a small but statistically significant decrease in stroke volume and cardiac output in the subjects, whereas heart rate and systolic blood pressure did not change. Changes in hemodynamic parameters occurred during the 20-min exposure to noise, and continued for $5 \mathrm{~min}$ after cessation of the exposure. All variables returned to baseline after 10 min of rest.
This study suggests that exposure to industrial noise level observed in the various industrial processes can cause significant increases in blood pressure and systemic vascular resistance. Animal studies also have shown that repeated increase in blood pressure after successive exposures to noise implies a permanent increase in blood pressure. Therefore, it has been postulated that the noise may be one of a number of external stimuli contributing to the development of hypertension in humans [10].

Impedance cardiography was also used to study the effects of high acceleration on the reaction of the circulatory system. Fighter pilots by virtue of their job are exposed to high overloads. The reaction of the circulatory system to the high acceleration was evaluated by Newman and Callister [11]. They have found that repeated exposure to high accelerations causes an increase in the mean resting arterial pressure (MAP) and heart rate. Such studies are important in the process of training pilots and may facilitate their adaptation to high accelerations [11].

Staying at high altitudes is an example of extreme conditions in which the cardiovascular system can be monitored using impedance cardiography. Using ICG, Krzesiński et al. [12] examined 13 participants of $2 \mathrm{Hi}$ malaya expeditions. The study was carried out before and during the expedition's stay at high altitudes (4300$5700 \mathrm{~m}$ ) with simultaneous assessment of clinical symptoms that may suggest acute mountain sickness (AMS) or an increased risk of high-altitude pulmonary oedema (HAPO). A large proportion of the expedition participants staying in the mountains showed hemodynamic changes (baseline vs. high altitude): stroke index (51.2 \pm 10.3 vs. $\left.35.5 \pm 11.3 \mathrm{ml} / \mathrm{m}^{2}, \mathrm{p}=0.0007\right)$; cardiac index $\left(3.24 \pm 0.49\right.$ vs. $\left.2.63 \pm 0.66 \mathrm{l} / \mathrm{min} / \mathrm{m}^{2}, \mathrm{p}=0.013\right)$; heart rate $(64.1 \pm 11.7$ vs. $75.4 \pm 15.41 / \mathrm{min}, \mathrm{p}=0.045)$; systemic vascular resistance index $(2051.3 \pm 438.9$ vs. $2668.4 \pm 856.2$ dyn $\times \mathrm{s} \times \mathrm{cm}^{-5} \times \mathrm{m}^{2}, \mathrm{p}=0.027$ ) [12]. Very interesting are the results of experiments conducted at elevated pressures. Cardiovascular response to 
the tilt test was examined in a group of 8 men who stayed for $15 \mathrm{~min}$ in hyperbaric environment ( $3 \mathrm{~atm} \mathrm{abs}$ ) at $31^{\circ} \mathrm{C}$ ambient air temperature. Heart rate, blood pressure and cardiac output were evaluated for $15 \mathrm{~min}$ before, during and after the exposure. The same experiment was repeated at $29^{\circ} \mathrm{C}$ and normal atmospheric pressure. Baseline heart rate was significantly lower at $3 \mathrm{~atm}$, while the increase in heart rate in response to the tilt test was similar in both experiments ( 15 beats/min). The decrease in systolic blood pressure in both environments was identical. Based on the experiment, it was found that a significant bradycardia which was recorded in subjects under hyperbaric conditions did not affect the normal response to orthostatic hypotension because of peripheral vasoconstriction caused by increased pressure of oxygen and an increase in systemic vascular resistance [13].

Exposure to cold and hemodynamic changes in those conditions were studied by Muller et al. (2010) [14]. They assessed the impact of periodic and continuous exercise on changes in body temperature and manual dexterity in cold microclimate $\left(5^{\circ} \mathrm{C}\right)$. The study group included 14 men aged $21 \pm 1$ years. They were exposed to cold for a period of $90 \mathrm{~min}$, followed by 30 -min exercise (riding a bicycle ergometer) continuously or intermittently and then $60 \mathrm{~min}$ of rest. Study participants were dressed in clothes of 1 clo (clothing insulation) but their hands were exposed. There was a sharp decline in manual dexterity after exposure to cold (before exercise). As expected, there was a drop in body temperature and manual dexterity after exposure to cold, followed by an increase of these parameters after the physical exercise for both periodic and continuous tasks. However, the continuous exercise proved to be more effective in restoring manual dexterity. Also, the mean values of the stroke volume were higher after continuous exercise $(116 \pm 36 \mathrm{ml})$ compared to the values obtained after intermittent exercise $(100 \pm 31 \mathrm{ml})$. The authors stress that further studies are needed to explain the changes that occur in the circulatory system after exposure to cold [14].

\section{PHYSICAL EXERCISE}

The effects of intense exercise on cardiovascular function were examined using impedance cardiography by Heydari et al. [15]. They conducted a study in a group of 38 young men (aged 24.9 \pm 4.3 years) with a body mass index (BMI) of 28.7 \pm 3.1 . A group of 20 people participated in the program of intense physical exercise for 12 weeks, and 18 control subjects were engaged in normal daily physical activity. The training program comprised ergometer exercise 3 times a week for 20 min during 12 weeks. Heart rate, stroke volume, cardiac output, pre-ejection period, left ventricular ejection time, both before exercise and after 12 weeks of training were determined by impedance cardiography. Analysis of the results showed a significant decrease in heart rate, increased stroke volume and increased ejection time of the left ventricle after 12 weeks of training in a group of people performing intense physical exercise. The study showed a favorable effect of exercise training on the cardiovascular system and the feasibility of the use of impedance cardiography for assessment of cardiovascular function [15].

Similar studies evaluating the effect of endurance training on cardiac morphology and left ventricular systolic and diastolic function were conducted by Yilmaz et al. [16]. The study participants included 79 healthy athletes (age: $20 \pm 2.6$ years, $49 \%$ men), while 82 healthy volunteers were recruited from the group of young people (age: $20.8 \pm 2.2$ years, $49 \%$ male) practicing sedentary lifestyle. Hemodynamic parameters were rated using impedance cardiography and echocardiography in all participants. In the group of athletes (both women and men) size of the left ventricle was larger and stroke volume increased compared to the control group. Male athletes had lower resting heart rate than women athletes, but their mean arterial pressure was higher. In the group of male athletes, a slight correlation was noted between stroke volume and the mass of the left ventricle. In addition, both morphological and hemodynamic differences were more evident 
in the group of male athletes. The results of those tests facilitate adequate training of athletes and selection of such loads that would not result in adverse health effects [16]. Use of endurance training may be considered in the treatment of orthostatic hypotension. This is the result of research on orthostatic intolerance syndrome. Winker et al. evaluated the effect of endurance training on the symptoms of orthostatic hypotension and its usefulness in the treatment of orthostatic hypotension. Endurance exercises were conducted in the form of 3 cycles of 4-week jogging. In each cycle, the duration of the training was extended. It was found that the endurance training resulted in better orthostatic tolerance in most patients. There was a decrease in heart rate and systemic vascular resistance in the subjects [17].

\section{IMPEDANCE CARDIOGRAPHY IN EXAMINATIONS OF DRIVERS}

Motor sports are a particular challenge for research on the cardiovascular system because of the extreme and highly variable factors acting on the body. Mallows et al. [18] determined hemodynamic parameters in race car drivers while driving. The study was designed to assess the quality and reliability of the data obtained in these unique conditions. The study group comprised 6 healthy race car drivers aged $23 \pm 2$ years, mean experience in racing $7 \pm 4$ years. Data were collected in an Australian racing track during training. Each driver had the hemodynamic parameters recorded using Holter impedance cardiography. The study did not in any way interfere with the process of driving. Baseline hemodynamic parameters were recorded at rest, then the driver run the distance of 10 lap race at a maximum speed of $280 \mathrm{~km} / \mathrm{h}$. The test conditions correspond to the conditions during the race (speed, acceleration, time to complete 1 lap).

The study confirmed that driving a car in such specific and extreme conditions increases heart rate and stroke volume compared to resting values. Ability to analyze changes in not only heart rate but also stroke volume of driver while driving is very important to monitor the condition of driver's cardiovascular system and his response to traffic conflict situations. The reported study has also confirmed that ICG can be used in such special conditions and does not adversely affect the quality of the results. Unfortunately, no results of such studies are accessible because it is virtually impossible to obtain consent from the concerned teams to perform such tests during real competition. From a technical standpoint, it is easier to conduct driver research in a driving simulator. It allows to simulate stressful and dangerous traffic situations in which a driver may happen to be involved during driving a vehicle. Fairclough et al. [19] studied 29 men aged $25.5 \pm 7.5$ years during simulated driving according to a specific scenario, which assumed driving both in the urban and suburban area for $15 \mathrm{~min}$. Arriving to the destination within the scenario-pre-set time was hindered by 2 traffic congestions that appeared on the road in the 2nd min and the 12th min of driving. Drivers had to obey the traffic rules, because their violation was punished. The aim of the study was to determine the driver's psychophysiological reactions to the 1st and the 2nd congestion. Psychological and ICG tests, blood pressure monitoring, facial electromyography, and EEG were performed in all participants.

After the simulated driving test, higher level of anger, higher heart rate and blood pressure, stroke volume, longer left ventricular ejection time, pre-ejection period and greater cardiac output compared to baseline were observed in the surveyed drivers. The increase in the value of individual parameters was higher while waiting in the 2nd than in the 1st traffic congestion, probably due to the fact that the drivers were already close to the destination and it intensified their anger. The results confirm the negative impact of anger and frustration on drivers' cardiovascular system, while the use of impedance cardiography makes it possible to measure the intensity of the hemodynamic changes. 
There is a close relation between the driver profession and the shift work, which is also known to adversely affect the cardiovascular system. The results obtained by Holmes et al. [20] suggest, based on impedance cardiography, that shift work has a direct and adverse effect on the activity of the autonomic nervous system, causing increased risk of cardiovascular disease. After a week of working the night shift, sleep deficit of the respondents was $5 \mathrm{~h} \pm 56 \mathrm{~min}$. The authors claim that sleep deficit is one of the causes of increased risk of cardiovascular disease in shift workers [20]. The use of impedance cardiography in studies of drivers makes it possible to evaluate the cardiovascular response to driving under different road conditions and assess the stress associated with conflict situations encountered during driving. The test results may be of great prognostic value, in particular for drivers with impaired cardiovascular system. The more so that the driver's profession is associated with increased risk of hypertension and ischemic heart disease. Understanding the pathomechanism of hypertension in individual drivers is expected to facilitate the use of targeted antihypertensive therapy, which would indirectly improve traffic safety.

\section{CONCLUSIONS}

Impedance cardiography seems to be a very good, although underappreciated diagnostic method. The data indicate that it can be used in a variety of environmental conditions (even extreme) and in different occupational groups. What may distinguish it from among the many research methods is the fact that it enables non-invasive monitoring of cardiac output, stroke volume and systemic vascular resistance in subjects performing various tasks. This offers the opportunity to evaluate changes in the circulatory system of workers exposed to various factors of work environment and at the same time take appropriate preventive measures. None of the conventional methods, such as e.g., 24-h Holter ECG monitoring, is able to provide such a broad spectrum of relevant data.
As the retirement age has been extended, the population of older workers will increase, thus aggravating the problem of cardiovascular diseases. The contemporary occupational medicine should use inexpensive and non-invasive diagnostic methods, as they can greatly facilitate implementation of preventive procedures intended to ensure good health to the population of workers.

\section{REFERENCES}

1. Vrijkotte TG, van Doornen LJ, de Geus EJ. Overcommitment to work is associated with changes in cardiac sympathetic regulation. Psychosom Med. 2004 Sep-Oct;66(5):65663, http://dx.doi.org/10.1097/01.psy.0000138283.65547.78.

2. Mezzacappa ES, Kelsey RM, Katkin ES. The effects of epinephrine administration on impedance cardiographic measures of cardiovascular function. Int J Psychophysiol. 1999;31(3):189-96, http://dx.doi.org/10.1016/S0167-8760(98) 00058-0.

3. Harris WS, Schoenfeld CD, Weissler AM. Effects of adrenergic receptor activation and blockade on the systolic preejection period, heart rate, and arterial pressure in man. J Clin Invest. 1967;46(11):1704-14, http://dx.doi.org/10.1172/ JCI105661.

4. Smith JJ, Muzi M, Barney JA, Ceschi J, Hayes J, Ebert TJ. Impedance-derived cardiac indices in supine and upright exercise. Ann Biomed Eng. 1989;17(5):507-15, http://dx.doi. org/10.1007/BF02368070.

5. Why YP, Bishop GD, Tong EM, Diong SM, Enkelmann HC, Khader M, et al. Cardiovascular reactivity of Singaporean male police officers as a function of task, ethnicity and hostility. Int J Psychophysiol. 2003 Aug;49(2):99-110, http://dx.doi.org/10.1016/S0167-8760(03)00082-5.

6. Salomon K, Bylsma LM, White KE, Panaite V, Rottenberg J. Is blunted cardiovascular reactivity in depression mood-state dependent? A comparison of major depressive disorder remitted depression and healthy controls. Int J Psychophysiol. 2013 Oct;90(1):50-7, http://dx.doi.org/10.1016/j.ijpsycho. 2013.05.018. 
7. Bosch JA, de Geus EJ, Carroll D, Goedhart AD, Anane LA, van Zanten JJ, et al. A general enhancement of autonomic and cortisol responses during social evaluative threat. Psychosom Med. 2009 Oct;71(8):877-85, http://dx.doi. org/10.1097/PSY.0b013e3181baef05.

8. Marrero AF, al'Absi M, Pincomb GA, Lovallo WR. Men at risk for hypertension show elevated vascular resistance at rest and during mental stress. Int J Psychophysiol. 1997 Apr;25(3):185-92, http://dx.doi.org/10.1016/S0 167-8760(96)00737-4.

9. Paunović K, Stojanov V, Jakovljević B, Belojević G. Thoracic bioelectrical impedance assessment of the hemodynamic reactions to recorded road-traffic noise in young adults. Environ Res. 2014 Feb;129:52-8, http://dx.doi.org/10.1016/ j.envres.2014.01.001.

10. Andrén L, Hansson L, Björkman M, Jonsson A. Noise as a contributory factor in the development of elevated arterial pressure. A study of the mechanisms by which noise may raise blood pressure in man. Acta Med Scand. 1980;207(6):493-8.

11. Newman DG, Callister R. Cardiovascular training effects in fighter pilots induced by occupational high $\mathrm{G}$ exposure. Aviat Space Environ Med. 2008 Aug;79(8):774-8, http://dx.doi. org/10.3357/ASEM.1575.2008.

12. Krzesiński P, Sadłoń NM, Grudzień KT, Gielerak G, Stańczyk A. Impedance cardiography as a tool for haemodynamic monitoring at high altitude: A preliminary study. Kardiol Pol. 2012;70(9):911-7.

13. Sagawa S, Miki K, Tajima F, Shiraki K. Cardiovascular responses to upright tilt in man during acute exposure to $3 \mathrm{~atm}$ abs air. Undersea Biomed Res. 1992 Mar;19(2): 97-106.

14. Muller MD, Ryan EJ, Bellar DM, Kim CH, Blankfield RP, Muller SM, et al. The influence of interval versus continuous exercise on thermoregulation, torso hemodynamics, and finger dexterity in the cold. Eur J Appl Physiol. 2010 Jul;109(5):857-67, http://dx.doi.org/10.1007/s00421010-1416-8.

15. Heydari M, Boutcher YN, Boutcher SH. High-intensity intermittent exercise and cardiovascular and autonomic function. Clin Auton Res. 2013 Feb;23(1):57-65, http://dx.doi. org/10.1007/s10286-012-0179-1.

16. Yilmaz DC, Buyukakilli B, Gurgul S, Rencuzogullari I. Adaptation of heart to training: A comparative study using echocardiography and impedance cardiography in male and female athletes. Indian J Med Res. 2013 Jun;137(6):1111-20.

17. Winker R, Barth A, Bidmon D, Ponocny I, Weber M, Mayr O, et al. Endurance exercise training in orthostatic intolerance: A randomized, controlled trial. Hypertension. 2005 Mar;45(3):391-8, http://dx.doi.org/10.1161/01.HYP. 0000156540.25707.af.

18. Mallows RJ, Newman DG. Cardiovascular data acquisition in a dynamic motion environment. Aviat Space Environ Med. 2008 Apr;79(4):416-9, http://dx.doi.org/10.3357/ ASEM.1483.2008.

19. Fairclough SH, Spiridon E. Cardiovascular and electrocortical markers of anger and motivation during a simulated driving task. Int J Psychophysiol. 2012 May;84(2):18893, http://dx.doi.org/10.1016/j.ijpsycho.2012.02.005.

20. Holmes AL, Burgess HJ, McCulloch K, Lamond N, Fletcher A, Dorrian J, et al. Daytime cardiac autonomic activity during one week of continuous night shift. J Hum Ergol. (Tokyo). 2001 Dec;30(1-2):223-8.

INNOVATIVE ECONOMY

NATIONAL COHESION STRATEGY

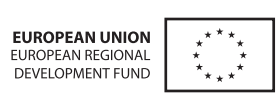

Project co-financed by the by the European Regional Development Fund under the Operational Programme Innovative Economy

This work is available in Open Access model and licensed under a Creative Commons Attribution-NonCommercial 3.0 Poland License - http://creativecommons.org/ licenses/by-nc/3.0/pl/deed.en. 